\title{
PENGARUH POLA ASUH ORANG TUA TERHADAP KECERDASAN INTRAPERSONAL DAN KECERDASAN INTERPERSONAL ANAK USIA DINI
}

\author{
Rahimah $^{1}$, Muzdhalifah ${ }^{2}$ \\ Universitas Islam Negeri Sunan Kalijaga Yogyakarta, Indonesia \\ HjRahimahPIAUD@gmail.com
}

\begin{abstract}
The purpose of this study is first, to know the categories parenting applied in kindergarten Pamardi Siwi. The second to know the level of the intelligence intrapersonal and interpersonal intelligence of children in kindergarten Pamardi Siwi. Third, to know the toward effect of parenting intrapersonal and interpersonal intelligence of children in kindergarten Pamardi Siwi.The type of the research is a field research that is descriptive with a quantitative approach.The results obtained after the calculation by hypothesis testing are: The most dominant parenting aolied in kindergarten Pamardi Siwi is democratic parenting. This is prover by the presentation of calculation as much as 21 respondents $(70 \%)$ in the category of democratic parenting, 6 respondents (20\%) in the category of permissive parenting, and 3 respondents (10\%) in the category of authoritarian parenting. Second, the level of children intrapersonal intelligence in Kindergarten Pamardi Siwi is 18 children developed very good category (BSB) which reach a percentage $(60 \%)$ than other categories, 10 respondents $(33.3 \%)$ in the category of developing according to expectations $(\mathrm{BSH})$ and 2 respondents $(6.7 \%)$ in the category begins to develop (MB). For the level of respondens' interpersonal intelligence in kindergarten Pamardi Siwi, is 23 respondents' (76.7\%) in the category of developing according to expectations (BSH), 4 respondents $(13.3 \%)$ in the category is growing very well (BSB) and a third of respondents $(10.0 \%)$ in the category begins to develop (MB). Third, the influence of parents' parenting towards intelligence intrapersonal and interpersonal intelligence. It is seen from the results of the analysis of $(X)$ to $(Y 1)$ obtained rxy1 $=433$, with the number of respondents to 30 children at a significance level of 0.05 rtabel $=0.361$ and 0.017 probability value. From these calculations indicate the probability $=0.017<0.05$ then $\mathrm{H} 0$ refused and Hi accepted. And for the analysis results $(\mathrm{X})$ to $(\mathrm{Y} 2)$ obtained rxy2 $=418$, with the number of respondents to 30 children at a significance level of $0.05 \mathrm{rtabel}=0.361$ and 0.022 probability value. From these calculations indicate the probability $=0.022<0.05$ then $\mathrm{H} 0$ refused and Hi accepted.
\end{abstract}

Keywords: Parenting Parents, Intrapersonal Intelligence, Interpersonal Intelligence.

\begin{abstract}
Abstrak
Tujuan dari penelitian ini adalah pertama, mengetahui ketegori pola asuh yang diterapkan di TK Pamardi Siwi. Kedua, mengetahui tingkat kecerdasan intrapersonal dan kecerdasan interpersonal anak di TK Pamardi Siwi. Ketiga, mengetahui pengaruh pola asuh orang tua terhadap kecerdasan intrapersonal dan kecerdasan interpersonal anak di TK Pamardi Siwi. Jenis penelitian dalam tesis ini adalah penelitian lapangan yang bersifat deskriptif dan uji inferensial dengan pendekatan kuantitatif. Hasil yang diperoleh setelah dilakukan perhitungan dengan pengujian hipotesis adalah: Pertama, pola asuh yang lebih dominan di terapkan di TK Pamardi Siwi ialah pola asuh demokratis. Hal ini dibuktikan dengan perhitungan presentasi sebanyak 21 responden (70\%) dalam kategori pola asuh demokratis, 6 responden (20\%) dalam kategori pola asuh permisif, dan 3 reponden (10\%) dalam kategori pola asuh otoriter. Kedua, tingkat kecerdasan intrapersonal anak di TK Pamardi Siwi ialah 18 responden kategori berkembang sangat baik (BSB) yang mencapai presentase $(60 \%)$ dari kategori yang lainnya, 10 responden $(33,3 \%)$ dalam kategori berkembang sesuai harapan $(\mathrm{BSH})$ dan 2 responden $(6,7 \%)$ dalam kategori mulai berkembang (MB). Untuk tingkat kecerdasan interpersonal di TK Pamardi Siwi, 23 anak $(76,7 \%)$ dalam kategori berkembang sesuai harapan (BSH), 4 responden $(13,3 \%)$ dalam kategori berkembang sangat baik (BSB) dan 3 responden $(10,0 \%)$ dalam kategori mulai berkembang (MB). Ketiga, adanya pengaruh pola asuh orang tua terhadap kecerdasan intrapersonal dan kecerdasan interpersonal. Hal ini dilihat dari hasil analisis $(X)$ terhadap $\left(Y_{1}\right)$ didapatkan $r_{x y 1}=433$, dengan jumlah responden 30 anak pada taraf signifikansi $0,05 r_{\text {tabel }}=0,361$ dan nilai probabilitas 0,017 . Dari perhitungan tersebut menunjukkan probabilitas $=$
\end{abstract}


Al Athfaal: Jurnal IlmiahPendidikanAnakUsiaDini

Vol.2 No.2 (2019) 1-13

p-ISSN : 2622-5484

http://ejournal.radenintan.ac.id/index.php/al-athfaal

e-ISSN : 2622-5182

Desember 2019

$0,017<0,05$ maka $\mathrm{H}_{0}$ ditolak dan $\mathrm{H}_{\mathrm{a}}$ diterima. Dan untuk hasil analisi $(\mathrm{X})$ terhadap $\left(\mathrm{Y}_{2}\right)$ didapatkan $\mathrm{r}_{\mathrm{xy} 2}=$ 418, dengan jumlah responden 30 anak pada taraf signifikansi $0,05 r_{\text {tabel }}=0,361$ dan nilai probabilitas 0,022. Dari perhitungan tersebut menunjukkan probabilitas $=0,022<0,05$ maka $\mathrm{H}_{0}$ ditolak dan Haditerima.

Kata Kunci : Pola Asuh Orang Tua, Kecerdasan Intrapersonal, Kecerdasan Interpersonal.

\section{PENDAHULUAN}

Pola asuh orang tua merupakan salah satu faktor penting dalam mengembangkan ataupun menghambat tumbuhnya pribadi dan kecerdasan. Seorang anak yang dibiasakan dengan suasana keluarga yang terbuka saling menghargai saling menerima dan mendengarkan pendapat anggota keluarganya. Maka ia akan tumbuh menjadi generasi yang terbuka, fleksibel, penuh inisiatif dan produktif suka akan tantangan dan percaya diri. (Yeni Rachmawati dan Euis Kurniati, 2017,p. 06)

Gaya-gaya pola asuh ke dalam gaya yang bersifat otoriter, demokratis, dan permisif. Gaya orang tua yang permisif ditandai oleh sifat menerima dan tidak menghukum dalam menghadapi perilaku anak-anak. Gaya orang tua yang otoriter menekankan kepatuhan terhadap aturan-aturan dan otoritas orang tua. Gaya demokratis menekankan suatu cara yang rasional, berorientasi pada isu "memberi dan menerima". Dari sinilah dapat ditarik kesimpulan bahwa keluarga yang berhasil mendidik anak-anaknya dengan gemilang jumlahnya belum memadai. Jadi keluarga yang berhasil mendidik anak-anaknya dengan pola asuh demokratis bisa dikatakan sebagai keluarga yang sukses. (John W. Santrock, 2013,p. 174).

Seperti halnya kecerdasan interpersonal. Anak yang cerdas dalam Interpersonal melibatkan kemampuan untuk memahami dan bekerja dengan orang lain, kemampuan berempati pada orang lain, kemampuan berteman, menilai orang lain dalam waktu beberapa detik, tampak sangat mengenal lingkungan, menikmati permainan kelompok, dan banyak bersosialisasi di sekolah atau di lingkungan tempat tinggal. (Thomas Amstrong, 2002,p. 33).

Begitu pula dengan kecerdasan Intrapersonal anak-anak yang mempunyai kecerdasan ini anak yang kecenderungan untuk diam, tapi melaksanakan tugas denga baik, cermat. Sikap dan kemampuan yang kuat, tidak mudah putus asa, kadang-kadang telihat keras, serta mampu mengekspersikan perasaan dan keinginan diri dengan baik. Bagaimana mungkin seorang anak dapat melakukan hal tersebut tanpa adanya dorongan dari orang terdekat yaitu orang tunya. (Thomas Amstrong, 2002,p. 34-35). 
Berdasarkan observasi kebeberapa sekolah, peneliti menemukan satu sekolah dimana anaknya itu sangat ketergantungan dengan orang tuanya. Selain itu yang terjadi di TK Pamardi Siwi Sleman Yogyakarta, berdasarkan observasi dan wawancara dengan guru d TK tersebut, dalam hal keterampilan intrapersonal dan interpersonal sangat bervariasi. Dalam beberapa kesempatan, ditemukan bahwa ada beberapa anak yang terlihat sangat ketergantungan dengan orang tuanya, misalnya orang tua tidak boleh keluar dari kelas, harus berada di sampingnya sampai pembelajaran berakhir, kalau ditinggalkan dia akan menanggis tidak mau mengikuti pembelajaran. selain itu ada juga anak yang bisa lepas dengan orang tuanya yang tidak ketergantungan bisa ditinggalkan setelah diantar orang tuanya kesekolah.

\section{METODE}

Metode penelitian yang digunakan peneliti dalam penelitian ini adalah penelitian kuantitatif adalah untuk menjelaskan fenomena dengan menggunakan data-data numerik, kemudian dianalisis yang umumnya menggunakan statistik. (Uhar Suharsaputra,2012,p.27). Pada penelitian ini, peneliti tidak terlibat dalam belajar-mengajar sehingga peneliti hanya sebagai observasi, melihat kegiatan belajar anak-anak yang menjadi sasaran penliti. Penelitian ini dilaksanakan di TK Pamardi Siwi Sleman Yogyakarta, pada tanggal 16 Januari sampai 30 Januari 2019, subyek yang dilibatkan dalam penelitian ini berjumlah 30 anak di kelas TK A dan B pada semester genap, beserta Orang tua anak berjumlah 30 orang. Dalam penelitian ini Orang tua dijadikan subjek sebagai pengisi angket Pola Asuh, yaitu untuk mengetahui pola asuh mana yang lebih dominan diterapkan orang tua dengan anaknya. Anak, Sebagai Subjek dijadikan sebagai observer, peneliti melihat anak dalam proses belajar, bermain, bersosialisasi dengan teman-teman, guru-gurunya, untuk mengetahui bagaimana tingkah laku kecerdasan intrapersonal dan kecerdasan interpersonalnya. Guru, sebagai pendidik dan orang yang melihat serta ikut serta dalam roses perkembagan kecerdasan intrapersonal dan kecerdasan interpersonal anak.

Teknik Pengumpulan Data, pada penelitian ini, teknik yang digunakan pneliti dalam memperoleh data-data tersebut adalah sebagai berikut: Menyerahkan Angket dengan Orang tua Anak dan Guru: Angket pola asuh bertujuan untuk mengetahui yang mana lebih dominan pengasuhan orang tua bagi anak-anaknya, apakah pola asuh demokratis, otoriter atau permisif. Angket bagi guru ialah angket untuk kecerdasan Intrapersonal dan kecerdasan interpersonal anak, yaitu bertujuan untuk mengetahui bagaimana tingkat kecerdasan intrapersonal dan intrapersonak anak, karena guru lebih dekat dengan anak dan lebih banyak mengetahui bagaimana tingkat kecerdasan anak masing-masing. Wawancara 
dengan guru Kelas: Tujuan dari wawancara ini adalah untuk memperkuat data kecerdasan anak selain dari angket pola asuh orang tua yang diisi oleh orang tua anak. Pertanyaan wawancara buat guru, Sesuai dengan indikator yang telah dipaparkan dalam kecerdasan intrapersonal dan interpersonal. Obervasi di kelas: Tujuan dari observasi di kelas adalah untuk memperkuat data dari orang tua dan memperkuat hasil dari wawancara dengan guru di kelas tersebut. Dalam observasi ini, peneliti melihat bagaimana kecerdasan intrapersonal dan interpersonal anak, secara satu persatu anak dilihat dengan berpedoman indikator kecerdasan intrainterpersonal. Wawancara dengan Anak-anak: Tujuan dari wawancara dengan anak ialah untuk lebih mengetahui sifat atau perilaku anak tentang kecerdasan intrapersonal dan interpersonal anak. dengan cara berbicara seperti biasa kepada anak, dan berpedoman dengan indikator kecerdasan tersebut. Dan Teknik Dokumentasi: dalam penelitian ini, adanya dukumentasi yaitu digunakan untuk mengetahui dan mencatat hal-hal yang berkaitan dengan data yang diperlukan dalam penelitian. Seperti, mendaftar nama anak, jumlah anak, dan semua data yang diperlukan dalam penelitian. Data yang diperoleh dianalisis untuk menentukan data kuantitatif yang selanjutnya diolah untuk menguji hipotesis.

Desain Penelitian, variabel peneitian adalah objek penelitian atau apa yang menjadi titik perhatian suatu penelitian. Adapun variabel dalam penelitian yaitu: Variabel Bebas, adalah pola asuh Orang Tua. Variabel Terikat, adalah keverdasan Intrapersonal dan Kecerdasan Interpersonal.

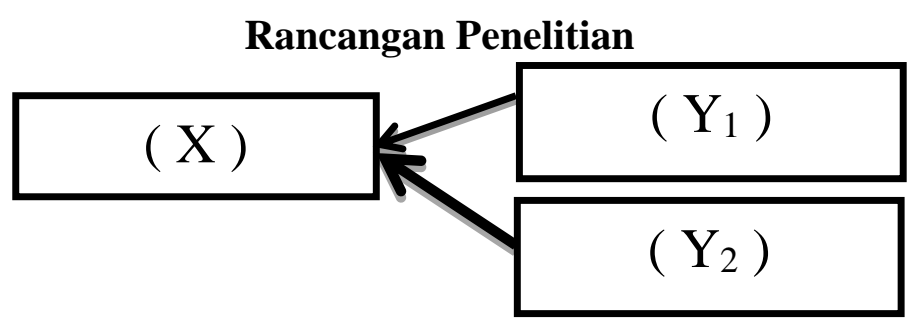

Teknik Analisis Data: Dalam penelitian Kuantitatif ialah data yang terkumpul selama melakukan penelitian perlu dianalisis dengan penuh ketelitian sehingga akan ditemukan suatu kesimpulan yang obyektif dari data yang diambil dalam penelitian. Validitas Tim Ahli: yaitu Uji validitas tim ahli ini dilakukan oleh validator yang diminta untuk memvalidasi butir-butir angket tersebut. Uji validitas: untuk mengetahui tingkat kevalidan suatu instrument yang diperoleh dari angket (kuesoner) untuk mendapatkan data tentang variabel (variabel pola asuh orang tua) dan variabel terikat (kacerdasan Intrapersonal dan kecerdasan interpersonal). Uji validitas dilakukan dengan rumus korelasi product moment 
dari pearson dengan syarat minimum dianggap valid adalah $r=0,361$. (Sadijono Anas, 2005,p.181).Reliabilitas: A reliable instrument is one that is consistent in what it measures. (Jack R. Fraenkel And Norman E. Wallen, 2003,p.47). Reliabilitas adalah ketepatan atau kebenaran alat tes, untuk menentukan reliabilitas perangkat soal, maka digunakan rumus alpha. Uji Normalitas: Uji Normalitas ini dimaksudkan untuk mengetahui apakah data tersebut berdistribusi normal atau tidak. Jika berdistribusi normal maka proses selanjutnya dalam pengujian hipotesis dapat menggunakan perhitungan statistik parametik dengan menggunakan uji kolmogorov-smirnov. ( Imam Machali,2018,p.104). Uji Linearitas: Untuk hubungan antara variabel X dan Variabel Y apakah linear atau tidak, maka perlu diadakan uji kelinieran dengan rumus F. (Sutrisno Hadi,

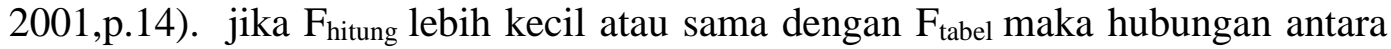
variabel terikat bersifat linier. Sebaliknya apabila harga $F_{\text {hitung }}$ lebih besar dari $F_{\text {tabel }}$ maka hubungannya antara variabel bebas dan variabel terikat bersifat tidak linierUji Hipotesis: Hipotesis dilihat dari kategori rumusannya dibagi menjadi dua, yaitu hipotesis nihil (Ho) dan hipotesis alternatif (Ha). Hipotesis nihil/nol (Ho) yaitu hipotesis yang menyatakan tidak adanya pengaruh antara variabel dengan variabel lain. Sedangkan hipotesis alteratif (Ha) yaitu hipotesis yang menyatakan adanya pengaruh antara variabel dengan variabel lain.Untuk menemukan arah dan kuatnya pengaruh antara dua variabel bebas dan variabel terikat digunakan uji korelasi dengan menggunakan rumus korelasi product moment.(Sutrisno Hadi, 2001,p.184).

\section{HASIL PENELITIAN (RESULT)}

Dalam penelitian ini angket merupakan alat untuk mengukur dan mengumpulkan sebuah data. Data tersebut yang meliputi data pola asuh orang tua $(\mathrm{X})$, Kecerdasan Intrapersonal $\left(\mathrm{Y}_{1}\right)$, dan Kecerdasan Interpersonal $\left(\mathrm{Y}_{2}\right)$. Hasil angket yang diisi dan telah dikumpulkan kemudian dikoreksi dengan standarisasi ukur penskoran yang telah disiapkan sebelumnya, sehingga setiap masing-masing variabel memiliki skor untuk setiap responden. Hasil dari perhitungan dalam penelitian ini adalah menggunakan analisi data melalui SPSS For Windows 17,0.

A. Distribusi Frekuensi

1. Pola Asuh Orang Tua (X), Data tentang pola asuh orang tua diperoleh melalui angket yang disi oleh orang tua anak dan acuan dalam pembuatannya mengacu pada indikator Pola Asuh Orang tua. Data angket terdiri dari 26 item pertanyaan yang terbagi 8 soal pola asuh demokratis, 9 soal pola asuh permisif, dan 9 soal pola asuh otoriter dengan alternatif jawaban SS, S, TS, STS dengan penskoran 4, 3, 2, 1 untuk pertanyaan positif, untuk pertanyaan negatif $1,2,3,4$. 
Tabel 1.1 Deskripsi Pola Asuh Orang Tua (X)

\begin{tabular}{|c|c|c|c|}
\hline No & Kategori & Jumlah & Presentase \\
\hline 1 & Demokratis & 21 & $70,0 \%$ \\
\hline 2 & Permisif & 6 & $20,0 \%$ \\
\hline 3 & Otoriter & 3 & $10,0 \%$ \\
\hline \multicolumn{2}{r|}{ Jumlah } & 30 & $100,0 \%$ \\
\hline
\end{tabular}

Berdasarkan hasil pengolahan data tersebut, maka dapat dijelaskan bahwa sebanyak 21 responden $(70,0 \%)$ dalam kategori pola asuh orang tua demokratis, sedangkan 6 responden $(20,0 \%)$ dalam kategori pola asuh orang tua permisif, Untuk 3 responden $(10,0 \%)$ dalam kategori pola asuh orang tua otoriter. Jadi dapat disimpulkan bahwa pola asuh orang tua di TK Pamardi Siwi Sleman Yogyakarta masuk dalam kategori pola asuh demokratis.

2. Kecerdasan Intrapersonal $\left(Y_{1}\right)$, Data tentang kecerdasan intrapersonal diperoleh melalui angket yang diisi oleh guru terdiri dari 14 item pertanyaan dengan alternatif jawbaan SS, S, TS, STS, dengan pesnskoran 4, 3, 2, 1 untuk pertanyaan positif, untuk pertanyaan negatif 1, 2, 3, 4. Jadi untuk jumlah skor maksmimal jika responden memperoleh skor 4 untuk seluruh item pertanyaan adalah 56, sedangkan skor minimal apabila responden memperoleh skor 1 adalah 14 .

Tabel 1.2 Deskripsi Kecerdasan Intrapersonal ( $\left.\mathbf{Y}_{1}\right)$

\begin{tabular}{|c|c|c|c|c|}
\hline No & Skor & Kategori & Jumlah & Presentase \\
\hline 1 & $76 \%-100 \%$ & BSB & 18 & $60,0 \%$ \\
\hline 2 & $51 \%-75 \%$ & $\mathrm{BSH}$ & 10 & $33,3 \%$ \\
\hline 3 & $26 \%-50 \%$ & MB & 2 & $6,7 \%$ \\
\hline 4 & $0 \%-25 \%$ & $\mathrm{BB}$ & 0 & $0,0 \%$ \\
\hline \multicolumn{3}{|c|}{ Jumlah } & 30 & $100,0 \%$ \\
\hline
\end{tabular}

Berdasarkan hasil pengolahan data tersebut, maka dapat dijelaskan bahwa sebanyak 18 responden $(60,0 \%)$ dalam kategori anak berkembang sangat baik (BSB), 10 responden $(33,3 \%)$ dalam kategori berkembang sesuai harapan (BSH), 2 responden $(6,7 \%)$ dalam kategori mulai berkembang (MB). Jadi dapat disimpulkan bahwa tingkat kecerdasan intrapersonal anak di TK Pamardi Siwi Sleman Yogyakarta masuk dalam kategori berkembang sangat baik (BSB).

3. Kecerdasan Interpersonal $\left(\mathrm{Y}_{2}\right)$, Data tentang kecerdasan interpersonal diperoleh melalui angket yang diisi oleh guru terdiri dari 14 item pertanyaan dengan alternatif jawbaan SS, S, TS, STS, dengan pesnskoran 4, 3, 2, 1 untuk pertanyaan positif, untuk pertanyaan negatif 1, 2, 3, 4. Jadi untuk jumlah skor maksimal jika responden memperoleh skor 4 untuk seluruh item pertanyaan adalah 56, sedangkan skor minimal apabila responden memperoleh skor 1 adalah 14 .

Tabel 1.3 Deskripsi Kecerdasan Interpersonal ( $\left.\mathbf{Y}_{2}\right)$

\begin{tabular}{|c|c|c|c|c|}
\hline No & Skor & Kategori & Jumlah & Presentase \\
\hline 1 & $76 \%-100 \%$ & BSB & 4 & $13,3 \%$ \\
\hline 2 & $51 \%-75 \%$ & BSH & 23 & $76,7 \%$ \\
\hline 3 & $26 \%-50 \%$ & MB & 3 & $10,0 \%$ \\
\hline
\end{tabular}




\begin{tabular}{|c|c|c|c|c|}
\hline 4 & $0 \%-25 \%$ & BB & 0 & $0,0 \%$ \\
\hline \multicolumn{3}{|c|}{ Jumlah } & 30 & $100,0 \%$ \\
\hline
\end{tabular}

Berdasarkan hasil pengolahan data tersebut, maka dapat dijelaskan bahwa sebanyak 4 responden $(13,3 \%)$ dalam kategori anak berkembang sangat baik (BSB), 23 responden $(76,7 \%)$ dalam kategori berkembang sesuai harapan $(\mathrm{BSH}), 3$ responden $(10,0 \%)$ dalam kategori mulai berkembang (MB). Jadi dapat disimpulkan bahwa tingkat kecerdasan interpersonal anak di TK Pamardi Siwi Sleman Yogyakarta masuk dalam kategori berkembang sesuai harapan (BSB).

B. Uji Normalitas

Pengujian normalitas menggunakan teknik One-Simple KolmogorovSmirnov Test pada prgram SPSS 17.0 For Windows. Hasil Uji normalitas dapat dilihat pada data berikut ini.

Tabel 1.4 Hasil Uji Normalitas

One-Sam ple Kolm ogorov-Sm irnov Test

\begin{tabular}{|lc|r|r|r|}
\hline & \multicolumn{1}{|c|}{$\begin{array}{c}\text { Pola } \\
\text { Asuh }(\mathrm{X})\end{array}$} & $\begin{array}{c}\text { Kecerdasan } \\
\text { Intrapersonal } \\
(\mathrm{Y} 1)\end{array}$ & $\begin{array}{c}\text { Kecerdasan } \\
\text { Interpersonal } \\
(\mathrm{Y} 2)\end{array}$ \\
\hline $\mathrm{N}$ & 30 & 30 & 30 \\
Normal a,b & Mean & 88,2333 & 42,0667 & 36,2333 \\
Parameters & Std. Deviation & 8,53263 & 5,55185 & 5,03562 \\
Most Extreme & Absolute &, 130 &, 170 &, 125 \\
Differences & Positive &, 111 &, 143 &, 125 \\
& $\quad$ Negative &,- 130 &,- 170 &,- 103 \\
Kolmogorov-Smirnov Z &, 711 &, 928 &, 683 \\
Asymp. Sig. (2-tailed) &, 693 &, 355 &, 739 \\
\hline
\end{tabular}

a. Test distribution is Normal.

b. Calc ulated from data.

Berdasarkan tabel di atas dapat diketahui bahwa seluruh data berdistribusi normal karena mempunyai hasil uji One-Simple KolmogorovSmirnov Test mempunyai nilai signifikansi 0,693 untuk variabel pola asuh orang tua, 0,355 untuk variabel kecerdasan intrapersonal dan 0,739 untuk variabel kecerdasan interpersonal. Syarat distribusi normal telah terpenuhi yaitu nilai signifikansi harus lebih besar dari 0,05.

C. Uji Linieritas

Tujuan dari uji linieritas adalah untuk mengetahui apakah diantara dua variabel $\mathrm{X}$ dan $\mathrm{Y}_{1}, \mathrm{Y}_{2}$ mempunyai hubungan yang linier secara signifikan atau tidak.

1. Uji Linieritas Pola Asuh (X) Terhadap Kecerdasan Intrapersonal ( $\left.\mathrm{Y}_{1}\right)$ 
Tabel 1.5 Uji Linieritas (X) Terhadap ( $\left.\mathrm{Y}_{1}\right)$

ANOV A Table

\begin{tabular}{|c|c|c|c|c|c|c|c|}
\hline & & & $\begin{array}{l}\text { Sum of } \\
\text { Squares }\end{array}$ & $d f$ & $\begin{array}{l}\text { Mean } \\
\text { Square }\end{array}$ & $F$ & Siq. \\
\hline \multirow{6}{*}{$\begin{array}{l}\text { Kecerdasan } \\
\text { ntrapersonal } \\
(\mathrm{Y} 1){ }^{*} \text { Pola } \\
\text { Asuh }(\mathrm{X})\end{array}$} & Betw een & (Combined) & 716,367 & 19 & 37,704 & 2,124 &, 111 \\
\hline & Groups & Linearity & 167,413 & 1 & 167,413 & 9,432 & ,012 \\
\hline & & Deviation & & & & & \\
\hline & & $\begin{array}{l}\text { from } \\
\text { Linearity }\end{array}$ & 548,954 & 18 & 30,497 & 1,718 & ,192 \\
\hline & \multicolumn{2}{|c|}{ Within Groups } & 177,500 & 10 & 17,750 & & \\
\hline & \multicolumn{2}{|l|}{ Total } & 893,867 & 29 & & & \\
\hline
\end{tabular}

Hasil uji linieritas pada tabel di atas, diketahui bahwa nilai signifikansi sebesar 0,192 lebih besar dari 0,05 dan nilai $F_{\text {hitung }}$ sebesar 1,718 dengan df 18/10, maka diperoleh nilai $F_{\text {tabel }}$ sebesar 2,798. Berdasarkan perhitungan dari uji linieritas diperoleh $F_{\text {titung }}$ lebih kecil dari $F_{\text {tabel, maka }}$ dapat disimpulkan bahwa antara variabel X (Pola Asuh Orang Tua) terhadap $\mathrm{Y}_{1}$ (Kecerdasan Intrapersonal) anak usia dini di TK Pamardi Siwi Sleman Yogyakarta adalah Linier.

2. Uji Linieritas Pola Asuh (X) Terhadap Kecerdasan Interpersonal ( $\left.\mathrm{Y}_{2}\right)$

Tabel 1.6 Uji Linieritas (X) Terhadap ( $\left.Y_{2}\right)$

ANOVA Table

\begin{tabular}{|c|c|c|c|c|c|c|c|}
\hline & & & $\begin{array}{l}\text { Sum of } \\
\text { Squares }\end{array}$ & df & $\begin{array}{l}\text { Mean } \\
\text { Square }\end{array}$ & $F$ & Sig. \\
\hline \multirow{5}{*}{$\begin{array}{l}\text { Kecerdasan } \\
\text { Interpersonal } \\
(\mathrm{Y} 2)^{*} \text { Pola } \\
\text { Asuh }(\mathrm{X})\end{array}$} & Betw een & (Combined) & 517,867 & 19 & 27,256 & 1,253 & ,368 \\
\hline & Groups & Linearity & 128,249 & 1 & 128,249 & 5,897 &, 036 \\
\hline & & $\begin{array}{l}\text { Deviation } \\
\text { from } \\
\text { Linearity }\end{array}$ & 389,617 & 18 & 21,645 & ,995 &, 525 \\
\hline & \multicolumn{2}{|c|}{ Within Groups } & 217,500 & 10 & 21,750 & & \\
\hline & \multicolumn{2}{|l|}{ Total } & 735,367 & 29 & & & \\
\hline
\end{tabular}

Hasil uji linieritas pada tabel di atas, diketahui bahwa nilai signifikansi

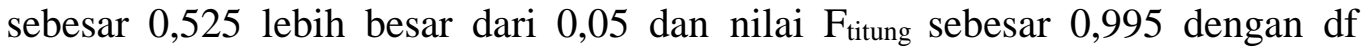
18/10, maka diperoleh nilai $F_{\text {tabel }}$ sebesar 2,798. Berdasarkan perhitungan dari uji linieritas diperoleh $\mathrm{F}_{\text {titung }}$ lebih kecil dari $\mathrm{F}_{\text {tabel, }}$ maka dapat disimpulkan bahwa antara variabel $\mathrm{X}$ (Pola Asuh Orang Tua) terhadap $\mathrm{Y}_{2}$ (Kecerdasan Interpersonal) anak usia dini di TK Pamardi Siwi Sleman Yogyakarta adalah Linier. 
D. Uji Hipotesis

Uji Hipotesis penelitian ini menggunakan teknik analisis korelasi product moment dengan menggunakan bantuan program aplikasi SPSS for windows 17,00 .

Tabel 1.7 Hasil analisis data Hipotesis SPSS Versi 17.00

\section{Cor relations}

\begin{tabular}{|c|c|c|c|c|}
\hline & & $\begin{array}{c}\text { Pola } \\
\text { Asuh (X) }\end{array}$ & $\begin{array}{c}\text { Kecerdasan } \\
\text { Intrapersonal } \\
(\mathrm{Y} 1)\end{array}$ & $\begin{array}{l}\text { Kecerdasan } \\
\text { Interpersonal } \\
(Y 2)\end{array}$ \\
\hline Pola Asuh (X) & $\begin{array}{l}\text { Pearson Correlation } \\
\text { Sig. (2-tailed) } \\
\mathrm{N}\end{array}$ & $\begin{array}{r}1 \\
30\end{array}$ & $\begin{array}{r}, 433^{*} \\
, 017 \\
30\end{array}$ & $\begin{array}{r}, 418^{*} \\
, 022 \\
30\end{array}$ \\
\hline $\begin{array}{l}\text { Kecerdasan } \\
\text { Intrapersonal } \\
(\mathrm{Y} 1)\end{array}$ & $\begin{array}{l}\text { Pearson Correlation } \\
\text { Sig. (2-tailed) } \\
\mathrm{N}\end{array}$ & $\begin{array}{r}, 433^{\star} \\
, 017 \\
30\end{array}$ & $\begin{array}{r}1 \\
30\end{array}$ & $\begin{array}{r}-, 039 \\
, 839 \\
30\end{array}$ \\
\hline $\begin{array}{l}\text { Kecerdasan } \\
\text { Interpersonal } \\
(\mathrm{Y} 2)\end{array}$ & $\begin{array}{l}\text { Pearson Correlation } \\
\text { Sig. (2-tailed) } \\
\mathrm{N}\end{array}$ & $\begin{array}{c}\text {,418* } \\
, 022 \\
30\end{array}$ & $\begin{array}{r}-, 039 \\
, 839 \\
30\end{array}$ & $\begin{array}{r}1 \\
30\end{array}$ \\
\hline
\end{tabular}

*. Correlation is significant at the 0.05 level (2-tailed).

1. Pengujian Hipotesis $X$ Terhadap $Y_{1}$

Hipotesis yang pertama menyatakan bahwa "Ada pengaruh pola orang tua terhadap kecerdasan intrapersonal di TK Pamardi Siwi Sleman Yogyakarta" Berdasarkan hasil perhitungan data diperoleh $r_{x y 1}=433$, dengan jumlah responden 30 anak pada taraf signifikansi $0,05 \quad r_{\text {tabel }}=0,361$ dan nilai probabilitas 0,017 . dari perhitungan tersebut menunjukkan probabilitas $=0,017$ $<0,05$ maka $\mathrm{H}_{0}$ ditolak sehingga hipotesis menunjukkan adanya pengaruh pola asuh orang tua terhadap kecerdasan intrapersonal di TK Pamardi Siwi Sleman Yogyakarta.

2. Pengujian Hipotesis $X$ Terhadap $Y_{2}$

Hipotesis yang kedua menyatakan bahwa "Ada pengaruh pola orang tua terhadap kecerdasan interpersonal di TK Pamardi Siwi Sleman Yogyakarta" Berdasarkan hasil perhitungan data diperoleh $r_{x y 2}=418$, dengan jumlah responden 30 anak pada taraf signifikansi $0,05 \quad r_{\text {tabel }}=0,361$ dan nilai probabilitas 0,022 . dari perhitungan tersebut menunjukkan probabilitas $=0,022$ $<0,05$ maka $\mathrm{H}_{0}$ ditolak sehingga hipotesis menunjukkan adanya pengaruh pola asuh orang tua terhadap kecerdasan interpersonal di TK Pamardi Siwi Sleman Yogyakarta. 


\section{PEMBAHASAN (DISCUSSION)}

Penelitian ini bertujuan untuk mengkaji pengaruh antara pola asuh orang tua terhadap kecerdasan intrapersonal dan kecerdasan interpersonal anak usia dini di TK Pamardi Siwi Sleman Yogyakarta. Penelitian ini menggunakan pendekatan kuantitatif yang didasarkan perhitungan persentasi dan perhitungan statistik.Variabel yang digunakan dalam penelitian ini adalah variabel bebas dan variabel terikat. Variabel bebas $(\mathrm{X})$ adalah pola asuh orang tua. Variabel terikat $\left(\mathrm{Y}_{1}\right)$ adalah kecerdasan intrapersonal, dan $\left(\mathrm{Y}_{2}\right)$ adalah kecerdasan interpersonal. Sampel yang digunakan dalam penelitian ini adalah peserta didik sebanyak 30 orang, namun cara pengumpulan datanya mengacu kepada 30 orang tua anak dan guru kelas A dan B di TK Pamardi Siwi Sleman Yogyakarta.

1. Pola Asuh Orang Tua di TK Pamardi Siwi Sleman Yogykarta. Berdasarkan diskriptif data menunjukkan bahwa sebanyak 21 responden $(70 \%)$ dalam kategori pola asuh demokratis.. Jadi dapat disimpulkan bahwa keadaan pola asuh orang tua di TK Pamardi Siwi Sleman Yogyakarta dalam kategori pola asuh demokratis. Orang tua yang terbuka, yaitu demokratis memberikan kesempatan kepada anak untuk masalah tertentu agar anak ikut berperan aktif dalam memutuskan. Peran orang tua sebagai pendamping lebih terlihat dalam memberikan pengarahan, petunjuk atau bantuan kepada anak. Dalam pola asuh demokratis, orang tua bersikap fleksibel, melakukan pengawasan dan tuntunan, tetapi juga hangat, rasional, dan mau berkomunikasi sehingga menjadikan anak tidak tergantung, mendorong anak untuk berprestasi, anak menjadi percaya diri, mandiri, imajinatif, mudah beradaptasi, kreatif, dan disukai banyak orang, serta responsif. Dari data dilapangan, observasi, dan hasil wawancara menyatakan bahwa anak di TK Pamardi Siwi yang pola asuhnya adalah demokratis, rata-rata orang tuanya mendidik anak-anaknya dengan kedisiplinan, keterbukaan, memotivasi, komunikasi yang baik, dan bimbingan yang baik. Dari beberapa anak yang pola asuhnya demokratis, peneliti melihat dan memperdalam satu anak yang bernama dimas, dari hasil wawancara dengan orang tuanya bahwa didikan orang tuanya adalah dengan cara selalu mendampingi ketika belajar, orang tuanya memberikan kebebasan kepada anaknya, bermusyawarah untuk menyelesaikan permasalahan, mengajarkan kepada anak jika ingin memberikan pendapat dipersilahkan.

2. Tingkat Kecerdasan Intrapersonal Anak di TK Pamardi Siwi Sleman Yogyakarta, berdasarkan diskriptif data menunjukkan bahwa sebanyak 18 responden $(60,0 \%)$ dalam kategori anak berkembang sangat baik (BSB). Jadi dapat disimpulkan bahwa Tingkat kecerdasan intrapersonal anak di TK Pamardi Siwi Sleman Yogyakarta masuk dalam kategori berkembang sangat baik (BSB). Artinya anak-anak yang memiliki kecerdasan intrapersonal yang tinggi cenderung memiliki pemahaman yang mendalam tentang diri mereka sendiri, apa kekuatan dan kelemahan dirinya, dan apa yang membuat dirinya unik. Menurut Asef Umar Fakhruddin, kecerdasan intrapersonal ialah kemampuan mengenali dan memahami diri sendiri serta berani bertanggung jawab atas perbuatannya sendiri. Anak-anak yang memiliki kecerdasan intrapersonal yang tinggi ia belajar sesuatu melalui diri sendiri. Mereka 
Al Athfaal: Jurnal IlmiahPendidikanAnakUsiaDini

Vol.2 No.2 (2019) 1-13

p-ISSN : 2622-5484

http://ejournal.radenintan.ac.id/index.php/al-athfaal

e-ISSN : 2622-5182

Desember 2019

mencermati apa yang mereka alami dan rasakan. (Asef Umar Fakhrudin,2010,p.142).

3. Tingkat Kecerdasan Interpersonal Anak di TK Pamardi Siwi Sleman Yogyakarta, berdasarkan diskriptif data menunjukkan bahwa 23 responden $(76,7 \%)$ dalam kategori berkembang sesuai harapan (BSH), Jadi dapat disimpulkan bahwa tingkat kecerdasan interpersonal anak di TK Pamardi Siwi Sleman Yogyakarta masuk dalam kategori berkembang sesuai harapan (BSH). Anak yang cerdas interpersonal, ia banyak mempunyai teman, bersosialisasi di manapun ia berada dan mampu menjaga hubungan sosial. Kecerdasan interpersoanl anak yang satu dengan yang lain tidaklah sama, masing-masing memiliki karakteristik yang berbeda. Anak yang cerdas tentunya banyak sekali faktor yang berperan di dalamnya, seperti keturunan, makanan sehat, perawatan, mental, dan lingkungan di mana anak berada.

4. Berdasarkan hasil menunjukkan bahwa pola asuh orang tua terhadap kecerdasan intrapersonal dan kecerdasan interpersonal berpengaruh. Adanya hubungan yang baik orang tua dan anak sehinga anak termotivasi. Sebuah keluarga dikatakan baik manakala terdapat karakteristik saling memperhatikan dan mencintai, bersikap jujur serta keterbukaan, orang tua mau mendengarkan anak, menerima perasaanya dan menghargai pendapatnya. (Tutu April Arini, 2009,p.67). Sikap kecerdasan intrapersonal anak ditandai dengan anak dapat menyelesaikan tugasnya dengan baik dalam menggambar, menulis, bermain tanpa disuruh, menunjukkan sikap percaya diri, senang mengajak temannya bermain, Diajarkan orang tuanya dengan cara selalu mendampingi anak belajar, menciptakan suasana belajar yang menyenangkan, sering bercakapcakap mengajak anak berbicara mencurahkan isi dan perasaannya, dan menemani anak dalam bermain. Sikap kecerdasan interpersonal anak ditandai dengan anak suka menolong teman, senang bermain dengan kelompok, mudah untuk mengenal orang yang baru, berani pergi dan pulang sekolah sendiri, senang meminjam atau tukaran mainan dengan temannya, sabar menunggu giliran. Diajarkan orang tuanya dengan cara melakukan kegiatan sosial dilingkungan. Sesuai dengan teori Howard Gardner kecerdasan interpersonal dipengaruhi oleh interaksi sosial lebih berperan penting dalam lingkungan, semakin baik interaksi sosial manusia maka semakin baik juga perkembangan kecerdasan interpersonal.

\section{SIMPULAN DAN SARAN (CONCLUSION AND RECOM MENDATION)}

Berdasarkan uraian yang telah dipaparkan dalam pembahasan dan analisis yang telah peneliti lakukan dengan berdasarkan pada rumusan masalah serta datadata yang diperoleh dari lapangan tentang pengaruh pola asuh orang tua terhadap kecerdasan intrapersonal dan kecerdasan interpersonal anak usia dini di TK Pamardi Siwi Sleman Yogyakarta.

1. Pola asuh Orang Tua di TK Pamardi Siwi Sleman Yogykarta. Berdasarkan diskriptif data menunjukkan bahwa sebanyak 21 responden $(70 \%)$ dalam kategori pola asuh demokratis, 6 responden (20\%) dalam kategori pola asuh permisif, dan 3 reponden (10\%) dalam kategori pola asuh otoriter. Jadi dapat 
disimpulkan bahwa keadaan pola asuh orang tua di TK Pamardi Siwi Sleman Yogyakarta dalam kategori pola asuh demokratis.

2. Tingkat Kecerdasan Intrapersonal Anak di TK Pamardi Siwi Sleman Yogyakarta, berdasarkan diskriptif data menunjukkan bahwa sebanyak 18 responden $(60,0 \%)$ dalam kategori anak berkembang sangat baik (BSB), 10 responden $(33,3 \%)$ dalam kategori berkembang sesuai harapan $(\mathrm{BSH}), 2$ responden $(6,7 \%)$ dalam kategori mulai berkembang (MB). Jadi dapat disimpulkan bahwa Tingkat kecerdasan intrapersonal anak di TK Pamardi Siwi Sleman Yogyakarta masuk dalam kategori berkembang sangat baik (BSB).

3. Tingkat Kecerdasan Interpersonal Anak di TK Pamardi Siwi Sleman Yogyakarta, berdasarkan diskriptif data menunjukkan bahwa sebanyak 4 responden $(13,3 \%)$ dalam kategori anak berkembang sangat baik (BSB), 23 responden $(76,7 \%)$ dalam kategori berkembang sesuai harapan $(\mathrm{BSH}), 3$ responden $(10,0 \%)$ dalam kategori mulai berkembang (MB). Jadi dapat disimpulkan bahwa Tingkat kecerdasan interpersonal anak di TK Pamardi Siwi Sleman Yogyakarta masuk dalam kategori berkembang sesuai harapan (BSB).

4. Pengaruh pola orang tua terhadap kecerdasan intrapersonal dan kecerdasan interpersonal. Hasil analisis menunjukkan bahwa pola asuh orang tua (X) memiliki peran penting dalam peningkatan kecerdasan intrapersonal dan kecerdasan interpersonal anak yang optimal. Dengan adanya pola asuh orang tua $(\mathrm{X})$ yang baik maka akan diperoleh kecerdasan yang baik pula. Begitu pula sebaliknya. Dari tabel correlations perhitungan hipotesis diperoleh skor untuk pola asuh orang tua $(\mathrm{X})$ terhadap $\left(\mathrm{Y}_{1}\right)$ Adalah $\mathrm{r}_{\mathrm{xy} 1}=433$, dengan jumlah responden 30 anak pada taraf signifikansi $0,05 \quad r_{\text {tabel }}=0,361$ dan nilai probabilitas 0,017 . dari perhitungan tersebut menunjukkan probabilitas = $0,017<0,05$ maka $\mathrm{H}_{0}$ ditolak sehingga hipotesis menunjukkan adanya pengaruh pola asuh orang tua terhadap kecerdasan intrapersonal di TK Pamardi Siwi Sleman Yogyakarta.

Dari tabel correlations perhitungan hipotesis diperoleh skor untuk pola asuh orang tua $(\mathrm{X})$ terhadap $\left(\mathrm{Y}_{1}\right)$ Adalah Berdasarkan hasil perhitungan $\mathrm{r}_{\mathrm{xy} 2}=418$, dengan jumlah responden 30 anak pada taraf signifikansi $0,05 r_{\text {tabel }}=0,361$ dan nilai probabilitas 0,022 . dari perhitungan tersebut menunjukkan probabilitas $=$ $0,022<0,05$ maka $\mathrm{H}_{0}$ ditolak sehingga hipotesis menunjukkan adanya pengaruh pola asuh orang tua terhadap kecerdasan interpersonal di TK Pamardi Siwi Sleman Yogyakarta.

Adapun saran dalampenelitianini:

1. Bagi para orang tua diharapkan dapat mempertahakan pola asuh yang sudah ada agar kecerdasan anak lebih berkembang lagi. Orang tua lebih mendekatkan kembali cara komunikasi dan cara mendidik yang baik kepada anaknya, agar merasakan kenyamanan saat sedang berada bersama keluarga. Melalui kebersamaan orang tua bisa menanamkan nilai-nilai yang dianut di keluarga agar anak di masa mendatang mengikutinya dengan baik.

2. Bagi para orang tua dapat memperhatikan penggunaan pola asuh sesuai situasi dan kebutuhan anak pada saat itu, dan jika dengan pola asuh diterapkan oleh orang tua ternyata tidak dapat mengembangkan kecerdasan anak, maka orang tua bisa mengganti dengan pola asuh yang lain. 


\section{DAFTAR RUJUKAN (REFERENCES)}

Rachmawati, Yeni, dan Euis Kurniati., 2017, Strategi Pengembangan Kreativitas pada Anak Usia taman kanak-kanak., Jakarta: Kencana.

Santrock, W John., 2013, Perkembangan Anak, Jakarta: Erlangga.

Armstrong, Thomas., 2002, Setiap Anak Cerdas, Jakarta: Pt Gramedia Pustaka Utama.

Suharsaputra, Uhar., 2012, Metode Penelitian, Bandung: PT Refika Aditama.

Anas, Sadijono., 2005, Pengantar Evaluasi Pendidikan, Jakarta: Raja Grafindo Persada.

Fraenkel, Jack R. and Norman E. Wallen., 2003, Student Workbook to Accompany How To Design and Evaluate Reseacrh In Education, New York: McGrawHill.

Hadi, Sutrisno., 2001, Analisis Regresi, Yogyakrta: Amdi Offset.

Machali, Imam., 2018, Metode Penelitian Kuantitatif, Yogyakarta: PPMPI.

Fakhruddin, Asef Umar., 2010, Menjadi Guru Favorit, Jogjakarta: Diva Press.

Arina, Tutu April., 2009, "Korelasi Pola Hubungan Orang tua dan Anak dan Keberfungsian Keluarga dengan Perkembangan Anak Usia Prasekolah", dalam Tesis Pendidikan Profesi Kesehatan. Universitas Sebelas Maret Surakarta. 